\title{
CROSS-SENSITIZATION BETWEEN IMMUNE AND NON-IMMUNE STRESSORS
}

\section{A Role in the Etiology of Depression?}

\author{
F. J. H. Tilders and E. D. Schmidt \\ Research, Institute Neurosciences Vrije Universiteit \\ Faculty of Medicine Department of Pharmacology \\ van der Boechorststraat 7, $1081 \mathrm{BT}$ Amsterdam, The Netherlands
}

\section{INTRODUCTION}

Organisms have a tremendous capacity to adapt to environmental conditions. This requires not only immediate responses to acute alterations in the internal or external milieu but also mechanisms that allow experiences to shape the response to later stimuli. Together with its genetic background, it are the specific experiences and their long lasting consequences that model the individual. Aspects of this can be found in almost all cells and organs, and are most prominent in the central nervous system and the immune system. The immune system shows an amazing capacity to store information about pathogens to the extent that a first encounter can prevent the organism from becoming ill by a renewed contact with the pathogen for a lifetime. Information about a wide variety of experiences can be stored in the brain to affect the responses to later events. How this information is stored is still poorly understood, but synaptic plasticity is generally considered to play a crucial role. Not only during early development but also in adulthood single or sporadic exposure to particular environmental stimuli can affect the response to the same stimulus weeks to years later. Such a change in response as a result of a specific earlier experience is often denoted as the "priming" effect of the stimulus. In its most simple form, priming can result in a reduction of the response to a second encounter, a phenomenon called desensitization, habituation or tolerance. Alternatively, priming may lead to exaggerated responses upon renewed exposure, a phenomenon known as sensitization. Both habituation and sensitization of brain-mediated responses represent expressions of neuro-plasticity in the adult brain and plays a key role in physiological adaptations but also in the etiology of various psychiatric diseases 
in particular of affective disorders. Habituation and sensitization of a wide variety of responses have been described including behavioral, metabolic, autonomous, neural, endocrine, and immune responses, and reflect altered vulnerability to a particular stimulus. In this chapter we will briefly describe long-lasting sensitization and crosssensitization to various stimuli as seen in adult animals, focus attention on immune activation induced long-lasting cross-sensitization, and discuss its possible contribution to the etiology of affective disorders.

\section{LONG-LASTING SENSITIZATION}

\subsection{Sensitization to Stressors}

In experimental animals and in humans, single or sporadic exposure to certain stimuli including stressors, immune activation, and drugs of abuse can result in long-lasting (weeks-lifetime) sensitization. Although the information is scarce, the mechanisms underlying long-lasting sensitization may be different from sensitization seen during chronic or repeated stimulation (Antelman \& Caggiula, 1996). In most chronic or repeated stress protocols that lead to sensitization, the neurochemical, behavioral, metabolic, and neuroendocrine responses undergo progressive alterations during stress exposure, and tend to return to their pre-stress profiles after cessation of the stress load (Van Dijken, 1992). Therefore, we and others have looked upon such chronic stress induced alterations as an effect of cumulation of rather short term effects (De Goeij, Binnekade, \& Tilders, 1992a). Long-lasting sensitization by a single event follows a different pattern. For instance, exposure of adult rats to a single and short $(15 \mathrm{~min})$ session of electric foot shocks induces behavioral sensitization to novel stressors, which progressively develops to reach a maximum approximately two weeks after the challenge (Van Dijken, Van Der Heijden, Mos, \& Tilders, 1992c), and can be maintained for two months as illustrated in Fig 1. Thus, behavioral sensitization can develop in the absence of further stimuli.

Because this pattern of behavioral sensitization is paralleled by sensitization of neuroendocrine and autonomic stress responses (Antelman, De Giovanni, \& Kocan, 1989, Fig 1B, 1C), this form of long- lasting stress sensitization may reflect a state of increased stress vulnerability as seen in various psychiatric disorders (Akil \& Ines Morano, 1995). In support of this, footshock-induced long-lasting behavioral sensitization was associated with increased anxiety related behavior, and anxiolytics were found to reverse these aberrant responses (Van Dijken, Mos, Van Der Heijden, \& Tilders, 1992a; Van Dijken, Tilders, Olivier, \& Mos, 1992b). Several other stressors including social defeat have been reported to induce alterations in behavioral and metabolic parameters that last for a week or more (Meerlo, Overkamp, \& Koolhaas, 1997; Sherman \& Petty 1982). Thus, although the effects of most stressors on subsequent responses dissipate within a few days, certain stressful events appear to provoke progressive and long-lasting alterations in stress responsive brain circuits that has precipitated in the "Once is enough" hypothesis (Van Dijken, 1992).

There is a large body of literature on long-lasting effects of perinatal stress exposure on stress vulnerability, stress responses and changes in brain stress circuits. Collectively, these observations show that the developing organism is extremely 
A

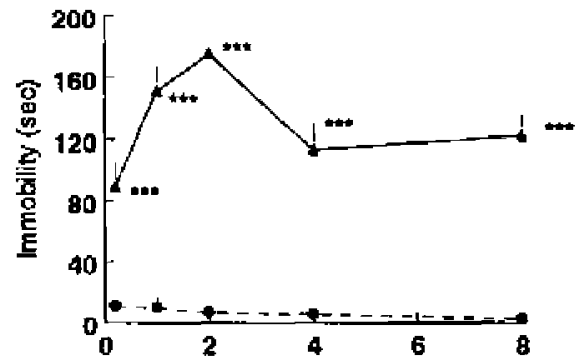

B

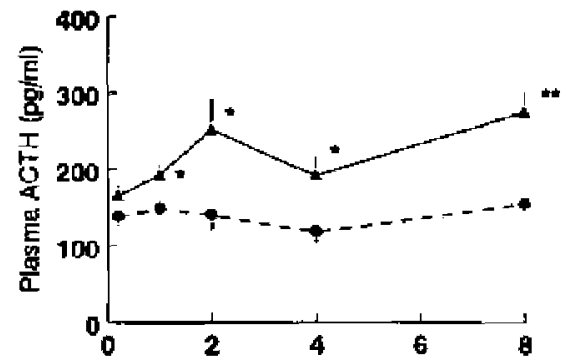

c

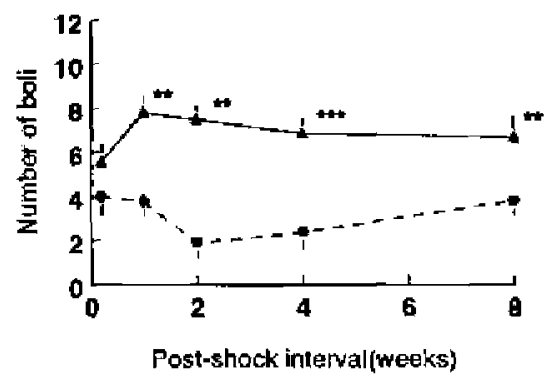

- - contral t- shocked

Figure 1. Long-lasting stress induced sensitization. Adult male rats were exposed to a single session of electric footshocks (shocked) or to the cage in which the shock was delivered without receiving electric current (control), and placed back in their home cage (Van Dijken et al., 1992a). At various time intervals thereafter ( 1 day- 8 weeks) groups $(n=8)$ of shocked and control rats were exposed to a novel environment (noise test, Van Dijken et al., 1992a,b). Their behavior was recorded for $3 \mathrm{~min}$ in the presence and absence of $65 \mathrm{~dB}$ white noise, and animals were decapitated immediately thereafter (cf. Van Dijken et al., 1993). Panel A: behavioral immobility expressed as cumulative duration during the $3 \mathrm{~min}$ noise off period. Panel B: plasma levels of AC'TH at the end of the noise test. Panel C: numbers of fecal boluses produced during the noise test, which serves as an index of autonomic reactivity. ${ }^{*} \mathrm{p}<0.05 ;{ }^{* *} \mathrm{p}<40.01 ;{ }^{* *} \mathrm{p}<0.001$ shocked vs time matched controls.

sensitive in the sense that stress shapes the individual's responses to stressors in later life (Meaney, Diorio, Francis, Widdowson, Laplante, Caldji, Sharma, Seckl, \& Plotsky, 1996; Weinstock, 1997). As discussed above, such long lasting sensitization is not an exclusive property of the developing brain. Also in adulthood certain stressors can affect stress responses and the underlying brain circuits for prolonged periods of time. 


\subsection{Sensitization to Drugs of Abuse}

Repeated exposure of experimental animals to drugs of abuse in particular to psychostimulants, can induce progressive and long-lasting (months) increases in behavioral responses induced by renewed drug exposure, and progressively increased motivational responses to obtain the drug. This "behavioral sensitization" to drugs of abuse is associated with lasting functional changes in certain brain circuits, i.e., mesolimbic dopamine systems (Kalivas \& Steward, 1991; Robinson \& Berridge, 1993). In humans, it is believed that the development of similar long-lasting neuroplastic changes determine the individual's vulnerability to drug addiction and relapse after detoxification. Studies in rats have demonstrated that sporadic or even single administration of a psychostimulant such as amphetamine or cocaine can lead to sensitization of the motivational, locomotor, neurochemical, and neuroendocrine i.e. hypothalamus-pituitary-adrenal (HPA) responses to the drug weeks later (Antelman, Eichler, Black, \& Kocan, 1980; MacLennan \& Maier, 1983; Robinson, 1984; Wilcox, Robinson, \& Becker, 1986; Paulson, Camp, \& Robinson, 1991; Steward \& Badiani, 1993; Schmidt, Tilders, Janszen, Binnekade, De Vries, \& Schoffelmeer, 1995b; Schmidt, Tilders, Binnekade, Schoffelmeer, \& De Vries, in press; De Vries, Schof-felmeer, Binnekade, Mulder, \& Vanderschuren, 1998). As for long-lasting sensitization to stressors, behavioral sensitization to drugs also appears to develop progressively in the absence of the stimulus. Several researchers demonstrated that neuroch-emical changes induced by chronic drug exposure show similarities with, but also differences from the long lasting changes seen after single or sporadic drug administration. This indicates that single and chronic drug administration can induce differential effects on the central nervous system.

\subsection{Sensitization to Immune Stimuli}

Activation of the immune system by pathogenic organisms or antigens leads to pathogen-specific responses of the immune system. In addition, immune stimuli elicit a host-defense response which is largely not pathogen specific. This non-specific illness response also occurs during tissue damage and inflammation and part of it is mediated by the brain. Thus, neuroendocrine, neurochemical, metabolic, and autonomic responses, and changes in mood, motivational state, sleeping patterns, eating behavior, social, and locomotor activities etc. all represent brain-mediated responses to illness (Kluger, 1991; Kent, Bluthe, Kelly, \& Dantzer, 1992; Tilders, De Rijk, Van Dam, Vincent, Schotanus, \& Persoons, 1994; Rothwell \& Hopkins, 1995; Besedovsky \& del Rey, 1996). The interest in these brain-mediated responses was boosted by the finding that endotoxins such as bacterial lipopolysacharide (LPS), and cytokines such as tumor necrosis factor alpha (TNF), interleukin-1 (IL-1), and IL-6 mimic most if not all of the brainmediated symptoms of illness induced by pathogens and inflammatory stimuli. How these large molecular cytokines, that cannot readily pass the blood-brain-barrier, affect the brain is still not fully understood but may involve neural afferents (Watkins, Wiertelak, Goehler, Mooney-Heiberger, Martinez, Furness, Smith, \& Maier, 1994; Gaykema, Dijkstra, \& Tilders, 1995; Rivest, 1995; Sehic \& Blatteis, 1996; Maier, Goehler, Fleshner, \& Watkins, 1998) and humoral mechanisms (Van Dam, De Vries, Kuiper, Zijlstra, Tilders, \& Berkenbosch, 1996; Tilders et al., 1994; Rivest, 1995; Ericsson, Liu, Hart, \& Sawchenko, 1995; Ericsson, Arias, \& Sawchenko, 1997).

A prominent symptom of illness is activation of the hypothalamus-pituitary- 
adrenal (HPA) system, which results in elevated plasma concentrations of adrenal glucocorticoids (cortisol, corticosterone). Because glucocorticoids exert potent anti-inflammatory activity and in general inhibit the production and effects of proinflamatory cytokines and other mediators, increased corticosterone levels are considered to play a crucial role in restraining the host-defense response. In its most typical form, immune activation by single administration of endotoxin, IL-1, IL-6 or TNF leads to transient activation of the HPA-system which, dependent on dose and route of administration, dissipates within 6-24 hours. After chronic administration of these cytokines, plasma ACTH, and corticosterone levels are initially elevated but progressively fall in time, which may point towards desensitization of the HPA system (Van der Meer, Sweep, Pesman, Tilders, \& Hermus, 1996). In an acute model of experimental allergic encephalomyelitis, which is a T-cell and macrophage mediated autoimmune response corticosterone levels increase in parallel with the severity of the neurological symptoms and normalize after their disappearance (MacPhee, Antoni, \& Mason, 1989). Experimental models of chronic inflammatory diseases such as adjuvant-induced arthritis show chronic activation of the HPA system (Sarlis, Chowdrey, Stephanou, \& Lightman, 1992; Harbuz \& Lightman, 1992) and reduced responses to stressors (Shanks, Harbuz, Jessop, Perks, Moore, \& Lightman, 1998). Thus, chronic immune stimulation may lead to desensitization of ongoing HPA responses.

In contrast, short immune activation by single administration of IL-1 to adult rats can increase the HPA response to a second stimulus one to two weeks later, showing that a single exposure to this immune stimulus induces long-lasting sensitization of the HPA response (Schmidt, Janszen, Wouterlood, \& Tilders, 1995a). Similar long-lasting (1-12 weeks) sensitization of the HPA response to IL-2 has been reported in humans (Denicoff, Durkin, Lotze, Quinlan, Davis, Listwak, Rosenberg, \& Rubinkow, 1989). Whether or not long lasting IL-1 induced sensitization of the HPA axis is associated with sensitization of other brain mediated host-defense responses is not clear (Anisman, Kokkinidis, Borowski, \& Merali, 1998). Preliminary findings do not show IL-1 induced long-lasting sensitization of the febrile response. In fact, this is not surprising because glucocorticoids are known to suppress the febrile response to IL-1 and other immune stimuli (Watanabe, Makisuma, Tan, Nakamori, Hakaura, \& Murakami, 1995). Therefore, exaggerated corticosterone responses may mask possible sensitization of brain mechanisms driving febrile or other illness responses. Alternatively, it is not inconceivable that immune activation induces long-lasting sensitization of some but not of other host-defense responses.

\section{LONG-LASTING CROSS-SENSITIZATION}

Long-lasting cross-sensitization of behavioral responses has been extensively described for drugs and stressors (Antelman et al., 1980; MacLennan \& Maier 1983; Wilcox et al., 1986; Robinson, Becker, Young, Akil, \& Castaneda, 1987). Here, we will focus on cross-sensitization of HPA responses. As described in section 2, stimuli of a widely different nature can induce long-lasting sensitization of the HPA system, i.e., lead to exaggerated ACTH and corticosterone responses upon renewed exposure to the same or a similar stimulus. Interestingly, sensitization may also lead to exaggerated HPA responses to stimuli of a different nature, a phenomenon denoted as "crosssensitization". For example, single administration of IL-1 to adult rats not only 
enhanced ACTH and corticosterone responses to IL-1, but also to electric foot shocks (Schmidt et al., 1995a) and amphetamine (Schmidt et al., in press). Similarly, electric foot shocks induce long lasting sensitization of the ACTH response to a novel environment (fig 1B, Van Dijken, De Goeij, Sutanto, Mos, De Kloet, \& Tilders, 1993) and cross-sensitization of the HPA response to amphetamine (Schmidt et al., in press). This is not to say that long-lasting sensitization is always associated with cross-sensitization of the HPA system to other stimuli. Nonetheless, available data indicate that single exposure of rats to IL-1 is particularly powerful in increasing HPA responses to immune stimuli, emotional stressors, and psychostimulant drugs for prolonged periods of time (weeks), and leads to the concept that transient immune activation can alter the individual's HPA response to stressors, and therefore affect its stress-vulnerability for prolonged periods of time.

\section{IMMUNE-INDUCED LONG-LASTING CHANGES IN THE HPA SYSTEM}

Let us consider the changes in the biological substrate that may underlie such long-lasting cross-sensitization. Because largely different brain circuits are involved in the activation of the HPA system by immune and emotional stressors (Sawchenko, Brown, Chan, Ericsson, Li, Roland, \& Kovacs, 1996), it was obvious to search for functional alterations within the HPA system rather than in stressor-responsive neural projections to the PVN. So far, long lasting alterations have been found at the level of the hypothalamic CRH neurons, of the pituitary gland and in feedback mechanisms. Before going into details of these changes it should be noted that single immune activation induces little or no long-term alterations in the resting levels of ACTH and corticosterone in the blood or the content of these hormones in the pituitary gland and adrenal gland respectively. Therefore, immune induced sensitization of the HPA system appears to be associated with altered responsivity rather than with altered resting activity of the HPA system.

Corticotropin Releasing Hormone $(\mathrm{CRH})$ producing neurons situated in the parvocellular part of the paraventricular nucleus (PVN), are activated by IL-1 and play a crucial role in IL-1 induced ACTH and corticosterone secretion (Berkenbosch, Van Oers, Del Rey, Tilders, \& Besedovsky, 1987; Rivest 1995; Ericsson et al., 1995; Gaykema et al., 1995). In collaboration with Aguilera's group in Bethesda, we found that 1-2 weeks after IL-1 priming, CRH neurons showed little or no changes in the expression levels of CRH mRNA, CRH peptide stores and CRH turnover (Schmidt et al., 1995a; Tilders et al., in prep). Another peptide that plays a prominent role in the control of ACTH secretion is vasopressin (AVP), which strongly potentiates the ACTH releasing effect of CRH. Although AVP is also produced by magnocellular neurons of the PVN and secreted from terminals in the posterior pituitary gland, various arguments support the view that AVP secreted from parvocellular CRH neurons represents the major potentiator of CRH mediated ACTH secretion (Whitnall, 1993; Kovacs \& Sawchenko 1996). In rodents and humans, hypothalamic CRH neurons can occur in two phenotypes (Whitnall, 1993; Raadsheer, Sluiter, Ravid, Tilders, \& Swaab, 1993; Raadsheer, Tilders, \& Swaab, 1994b). Under resting conditions, only part of these CRH neurons belong to the AVP co-producing phenotype, i.e., co-express AVP mRNA, co-produce, co-store, and co-secrete AVP with CRH (De Goeij et al., 1992a; De Goeij, Dijkstra, \& Tilders, 1992b; Whitnall, 1993; Bartanusz, Jezova, Bertini, Tilders, Aubry, \& Kiss, 1993). 
In collaboration with Verwer in Amsterdam, we found that the numbers of presumed CRH neurons that express AVP mRNA had increased 1-2 weeks after IL-1 priming. This is in accordance with an increase in the fraction of CRH terminals that co-store AVP (Schmidt et al., 1995a) and shows that IL-1 induces long-lasting changes in the phenotypic expression of $\mathrm{CRH}$ neurons. Moreover, following a single IL-1 challenge, terminals of $\mathrm{CRH}$ neurons in the median eminence showed a delayed ( $>4$ days) but long lasting (1-3 weeks) increase in AVP stores as illustrated in Fig 2. Therefore, the composition of ACTH secretagogues that are produced by hypothalamic CRH neurons is altered for prolonged periods of time after a single IL-1 exposure (Tilders \& Schmidt, 1998). Peptide turnover studies (Schmidt et al., 1995a) further support the view that the signal which is produced by hypothalamic CRH neurons, had shifted towards AVP domination which is reminiscent of changes found after adrenalectomy, chronic stress (Whitnall, 1993; Tilders, Schmidt, \& De Goeij, 1993; Aguilera, 1994), and depression (see below).

At the level of the pituitary gland, IL-1 priming did not affect steady state levels of POMC mRNA, POMC hnRNA, CRH receptor mRNA, and of CRH and vasopressin receptors (Tilders et al,, in prep). However, alterations were disclosed when IL-1 primed animals were challenged to mount an ACTH response. In vivo studies revealed that IL-1 priming increased the ACTH response to an AVP challenge but attenuated the ACTH response to $\mathrm{CRH}$. Thus, although the levels of $\mathrm{CRH}$ receptors and $\mathrm{CRH}$ receptor $\mathrm{mRNA}$ and their kinetics in the pituitary gland seem relatively intact, CRH effects in the pituitary gland are suppressed, which may hint to alterations in post-receptor mechanisms. Re-exposure of IL-1 primed rats to IL-1 revealed that the rapid down regulation of AVP receptors as seen in vehicle-primed animals was obliterated (Tilders et al., in prep). Thus, the mechanisms that appear to terminate AVP signaling in the pituitary gland are shut down in IL-1 primed animals, and AVP signaling is enhanced. The alterations in the pituitary gland therefore do not seem to compensate for the increased AVP drive by hypothalamic CRH neurons, but rather amplify the impact of enhanced AVP exposure during the challenge (see Fig 3).

In vivo studies further demonstrate that resting and stressor induced plasma

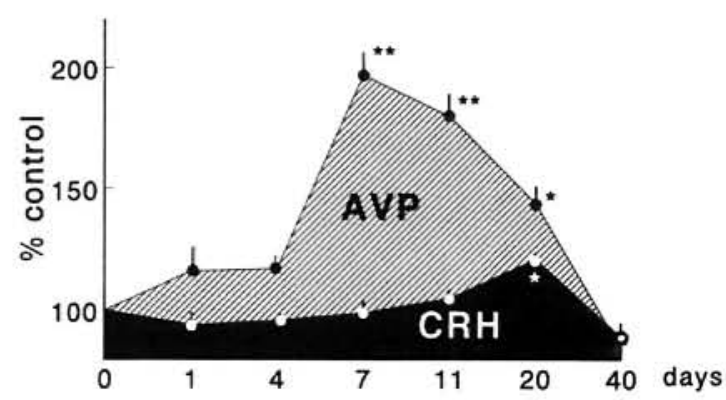

Figure 2. Long-lasting immune stimulus induced effects on hypothalamic CRH neurons. Adult rats were given a single dose of human recombinant interleukin-1 (IL-1) or vehicle (control). At various time intervals thereafter ( $1-40$ days) hypothalami of $1 L-1$ primed and vehicle primed rats $(n=8)$ were processed for quantitative immunocytochemical determination of CRH and vasopressin (AVP) in the external zone of the median eminence (terminals of hypophysiotropic CRH neurons). Note the delayed ( $>4$ days) and long lasting (7-20 days) increase in AVP signal. ${ }^{*} \mathrm{p}<0.05 ;{ }^{* *} \mathrm{p}<0.01$ vs vehicle primed time-matched controls. For details see: Schmidt et al., 1995a. 

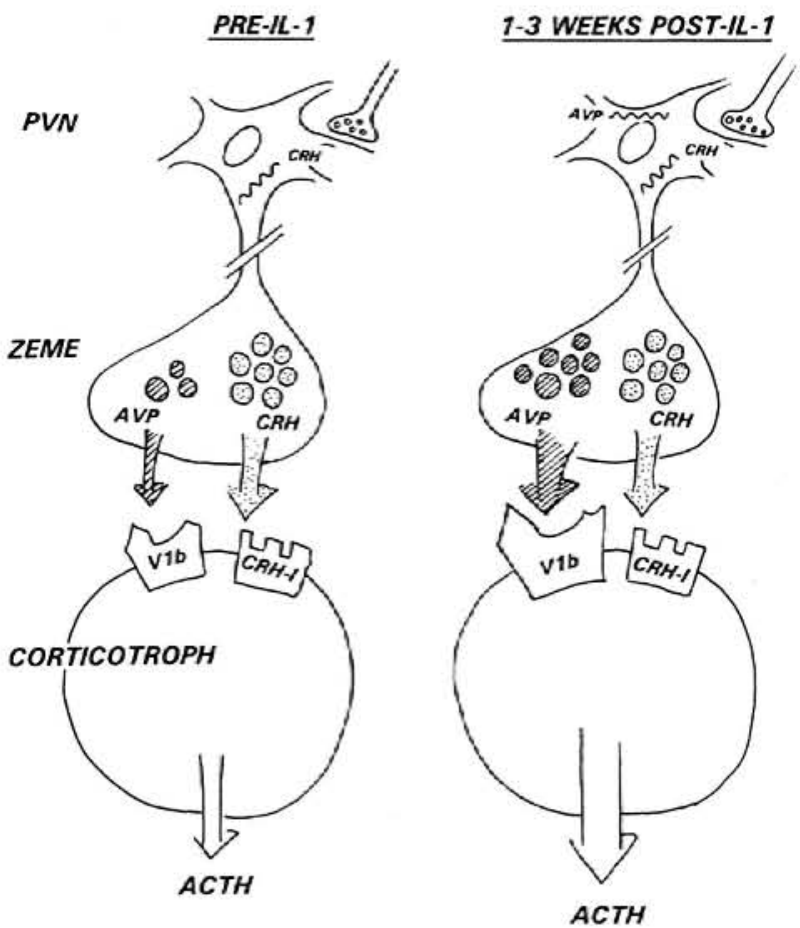

Figure 3. Schematic representation of immune-activation induced long-lasting alterations in hypothalamic $\mathrm{CRH}$ neurons and pituitary corticotrophs. PVN: paraventricular nucleus of the hypothalamus where cell bodies of hypophysiotropic CRH neurons are lacated. ZEME: external zone of the median eminence where the terminals of these neurons are located. Receptor mechanisms for CRH and AVP signaling are depicted as V1b and CRH-1 respectively. For details see text.

corticosterone levels of IL-1 primed rats were less sensitive to the suppressive actions of dexamethasone as compared to those in non-primed animals (Tilders et al., in prep), which reflects a partial glucocorticoid feedback deficiency for prolonged periods of time. The underlying processes may relate to alterations in glucocorticoid receptor mechanisms in the pituitary gland and/or the brain. Alternatively, because AVPmediated ACTH secretion as compared to CRH-mediated ACTH secretion is rather insensitive to glucocorticoid inhibition (Abou-Samra, Catt, \& Aguilera, 1986; Aguilera, 1994), this may as well be a reflection of the increased contribution of AVP to the control of ACTH secretion.

Although alterations at other levels cannot be excluded, the present findings strongly support the concept that long lasting alterations in hypothalamic CRH neurons and in pituitary corticotrophs are instrumental in IL-1 induced long-lasting sensitization of the HPA system.

\section{STIMULI INDUCING CROSS-SENSITIZATION AND NEUROPLASTICITY}

In view of the above mentioned findings, we studied whether a similar relationship between long-lasting cross-sensitization and neuroplastic changes in hypothalamic 
CRH neurons as induced by IL-1 also occurs after other stimuli. In other words, do different stimuli that induce long-lasting cross-sensitization of HPA responses, all induce similar neuroplastic changes in hypothalamic CRH neurons and vice versa? This is most probably not the case. Let us consider the effects of different manipulations of adult male rats on AVP stores in CRH terminals in the median eminence as an index of AVP hyperproduction in CRH neurons. As summarized in Table 1, various stimuli lead to increased AVP stores 1-3 weeks after the primary event, whereas other stimuli, including cocaine (Schmidt et al., 1995b), amphetamine (Schmidt et al., in press) novel environment, ether, restraint, insulin induced hypoglycemia (Schmidt, Binnekade, Janszen, \& Tilders, 1996), road transport from the animal supplier facilities to our labs (unpublished observations), and social defeat (Buwalda, De Boer, Schmidt, Sgoifo, Van Der Vegt, Tilders, Bohus, \& Koolhaas, in press) do not,

Earlier, we proposed that the power of the stimulus as reflected in the overall ACTH secretion (amplitude and duration) may determine long-lasting AVP hyper production in CRH neurons (Schmidt et al., 1996). Some novel observations are at odds with this view. For instance, social defeat which is a very strong stimulus for the HPA system (Buwalda et al., in press), does not affect AVP stores in CRH neurons. Based on all presently available data (see Table 1) we hypothesize that possibly not the intensity, but rather the nature of the stimulus primarily determines whether hypothalamic CRH neurons will increase their AVP production for prolonged periods of time and thereby produce an intrinsically more powerful ACTH releasing signal.

Conditions that did result in long-lasting increases in AVP stores in CRH neurons include inflammatory stimuli that can stimulate the production of cytokines in the brain. For instance, peripheral administration of endotoxin has been reported to result in IL-1 expression in the brain (Van Dam, Bauer, Tilders, \& Berkenbosch, 1995; Buttini \& Boddeke, 1995; Gabellec, Griffais, Fillion, \& Haour, 1995; Salta, Jacobs, Kaltsas, \&

Table 1. Long-lasting effects of various stimuli on CRH neurons and HRA sensitization. Adult male rats were subjected to a single exposure to one of various stimuli or to control conditions. Changes in CRH and AVP stores in CRH terminals in the external zone of the median eminence (ZEME) were measured 1-3 weeks later by quantitative immunocytochemistry (cf. Schmidt et al., 1996). In separate experiments, groups of rats were exposed to a challenge of the same nature 1-3 weeks after the priming stimulus and $\mathrm{ACTH}$ and/or cort responses were monitored

\begin{tabular}{lccc}
\hline & \multicolumn{2}{c}{ Peptide stores in ZFMF } & \\
\cline { 2 - 4 } Stimulus & CRH & AVP & Sensitization of HPA-response \\
\hline Footshocks & $\rightarrow$ & $\uparrow$ & $\uparrow$ \\
IL-1 i.p. & $\rightarrow \uparrow$ & $\uparrow$ & $\uparrow$ \\
IL-1 i.c.v. & $\rightarrow$ & $\uparrow$ & $?$ \\
Brain surgery & $\rightarrow$ & $\uparrow$ & $?$ \\
l.PS i.p. & $\rightarrow$ & $\uparrow$ & $?$ \\
Social defeat & $\rightarrow$ & $\rightarrow$ & $\uparrow$ \\
Hypoglycaemia & $\rightarrow$ & $\rightarrow$ & $?$ \\
Restraint & $\rightarrow$ & $\rightarrow$ & $?$ \\
Ether & $\rightarrow$ & $\rightarrow$ & $\rightarrow$ \\
Road transport & $\rightarrow 1)$ & $\rightarrow 1$ & $2)$ \\
Cocaine & $\rightarrow$ & $\rightarrow$ & $\uparrow$ \\
Amphctamine & $\rightarrow$ & $\rightarrow$ & $\uparrow$ \\
\hline
\end{tabular}

$\rightarrow:$ no change; $\uparrow:$ increase; ? not determined; 1) control groups were sacrificed at the animal suppliers facilities; 2) all animals have this history. For references see text. 
Grossman, 1998). Similarly, peripheral and central administration of IL-1 has been reported to increase IL-1 transcription in the brain (Plata-Salaman \& Ilyin 1997; Hansen, Taishi, Chen, \& Krueger, 1998) and also brain injury/surgery is known to induce local IL-1 transcription (Fan, Young, Barone, Feuerstein, Smith, \& McIntosh, 1995). Under certain experimental conditions, also electric foot shocks can induce IL-1 protein in the brain (Nguyen, Deak, Owens, Kohno, Fleshner, Watkins, \& Maier, 1998). Therefore, we speculate that cytokines that are produced in the brain in response to these stimuli may play a role in the cascade of events that result in long-lasting changes in the phenotype of hypothalamic CRH neurons.

\section{DEPRESSION-ASSOCIATED ALTERATIONS IN THE HPA SYSTEM}

Functional changes often referred to as dysregulations of the HPA system have been extensively documented in patients with depression (Akil \& Ines Morano, 1995; Post \& Weiss, 1995; Holsboer \& Barden, 1996). These include increased episodes of ACTH and cortisol secretion, elevated mean cortisol levels in the blood and increased free urinary cortisol levels. Various observations from both clinical and experimental animal studies support a causal link between dysregulation of the HPA system and psychopathology. Increased episodes of enhanced cortisol levels will lead to overexposure of the brain to this glucocorticoid and will affect the functioning of limbic forebrain structures including the hippocampus that are involved in processing of cognitive stimuli and the regulation of mood, learning, and memory processes, as well as aminergic systems in the brain stem that play a role in arousal and appraisal of environmental stimuli (De Kloet \& Joels, 1996; Joels, 1997). Glucorticoid induced alterations in the functioning of these brain structures as seen in chronic stress and depression in turn, are believed to facilitate activation of hypothalamic CRH neurons, and thereby sustain enhanced cortisol exposure (McEwen \& Sapolsky, 1995). There is an ongoing debate as to the initial changes that drive the hyperactivity of the HPA system in depressed patients. One of the hypotheses concerns an acquired or inherited glucocorticoid feedback resistance (De Kloet, Vreugdenhil, Oitzl, \& Joels, 1997). In accordance with this hypothesis, deficient cortisol responses to dexamethasone have been reported in up to $50 \%$ of patients with major depression. The finding that relatives of depressed patients that are at genetic risk for developing the disease, show excessive cortisol responses in combined dexamethasone/CRH tests (Holsboer, Lauer, Schreiber, \& Krieg, 1995) further supports the view that disturbances of glucocorticoid feedback (which is crucial for the normal functioning of the HPA system) represent a risk factor for the development of depression (Young, Haskett, Murphy-Weinburg, Watson, \& Akil, 1991). In addition, increased AVP production and secretion by hypothalamic CRH neurons which is known to occur in depression (see below) may generate a less glucocorticoid suppressible signal for ACTH release (Aguilera 1994, Von Bardeleben, Holsboer, Stalla, \& Muller, 1985).

$\mathrm{CRH}$ provocation studies in depressed patients revealed blunted ACTH but normal cortisol responses relative to controls. It is reasoned that the defective ACTH response may be due to reduced $\mathrm{CRH}$ receptor efficacy. Alternatively, elevated cortisol levels may account for the blunted ACTH response by their feedback action at the pituitary gland (Von Bardeleben, Stalla, Muller, \& Holsboer, 1988). The dissociation of $\mathrm{ACTH}$ and cortisol responses to a $\mathrm{CRH}$ challenge points to yet another level 
of dysregulation in the system. Together with enhanced cortisol responses to ACTH, these findings indicate that adrenal glands of depressed patients are hyper-responsive to circulating ACTH. In support of this, computer tomography studies revealed adrenal enlargement in major depressed patients (Nemeroff, Krishnan, Reed, Leder, Beam, \& Dunnick, 1992) which disappears after successful treatment (Rubin, Phillips, Sadow, \& McCracken, 1995). What exactly controls the changes in adrenal volume and responsiveness is not known but non-ACTH mechanisms including intra-adrenal CRH production (Van Oers, Hinson, Binnekade, \& Tilders, 1992) and increased sympathetic drive (Dijkstra, Binnekade, \& Tilders, 1996) are potential candidates.

In major depression, dysregulation of the HPA system is associated with increased activity of hypothalamic CRH neurons. This is supported by increased CRH concentrations in the CSF of depressed patients (Nemeroff, Widerlov, Bissette, Walleus, Karlsson, Eklund, Kilts, Loosen, \& Vale, 1984). Furthermore, CRH mRNA is markedly increased in the PVN of major depressives (Raadsheer, Van Heerikhuizen, Lucassen, Tilders, \& Swaab, 1995) and the numbers of CRH immunoreactive neurons and the numbers and of CRH neurons that co-express AVP are strongly increased in depressed patients (Raadsheer, Hoogendijk, Stam, Tilders, \& Swaab, 1994c; Swaab 1997). Several mechanisms may be involved in the hyper-activation of these neurons in depression including excessive stimulatory input from sensitized limbic or brainstem neurons, reduced input from inhibitory circuits, or intrinsic changes in $\mathrm{CRH}$ neurons such as reduced glucocorticoid receptor function in CRH neurons (De Kloet et al., 1997) or altered efficacy of efferent signal transfer to CRH neurons.

\section{IMMUNE ACTIVATION INDUCED HPA CHANGES AND DEPRESSION}

Several of the long-lasting immune stimulus induced alterations found in rats are also seen in depressed patients (see Table 2). As outlined above, alterations at these levels are most probably instrumental for the sensitization of the HPA system as seen in both conditions. Therefore, we hypothesize that in humans as in rats, transient activation of the immune system may result in a period of HPA sensitization and changes in CRH neurons. During this period of HPA sensitization, the ACTH and cortisol responses to internal or external stimuli are supposedly enhanced and therefore this period reflects a state of increased vulnerability to stressors. Based on animal

Table 2. Long-lasting immune stimulus induced and depression associated changes in the HPA system. Note the similarities of alterations at hypothalamic and pituitary levels, but not at the level of the adrenal gland (for details see text)

\begin{tabular}{lcc}
\hline Variables & Long-lasting immune induced & Depression associated \\
\hline AVP expression in CRH neurons & $\uparrow$ & $\uparrow$ \\
CRH expression in CRH neurons & $\rightarrow / \uparrow$ & $\uparrow$ \\
AVP/CRH signal & $\uparrow$ & $\uparrow$ \\
Pituitary response to CRH & $\downarrow$ & $\downarrow$ \\
Pituitary response to AVP & $\uparrow$ & $?$ \\
Glucocorticoid feedback & $\downarrow$ & $\downarrow$ \\
Resting cortisol/corticosterone levels & $\rightarrow$ & $\uparrow$ \\
Adrenal response to ACTH & $\rightarrow$ & $\uparrow$ \\
Adrenal mass & $\rightarrow$ & $\uparrow$ \\
\hline
\end{tabular}


studies, we propose that this vulnerable state in humans is also transient, and will fade after some time, that is if no major second event occurs within this time domain. During this vulnerable period, CRH neurons and pituitary corticotrophs may show functional changes but these do not lead to altered resting cortisol levels and readjust by the end of this period of stress sensitization. Although sensitization (Antelman et al., 1989) and increased cortisol responses may be advantageous in some conditions, they represent a risk factor for the development of pathology (Munck, McGuire, \& Holbrook, 1984; De Kloet \& Joels, 1996; De Kloet et al., 1997). If during the period of stress sensitization the individual faces another sensitizing stimulus (immune or otherwise), the exaggerated HPA response may be followed by further alterations in $\mathrm{CRH}$ neurons and pituitary corticotrophs, further increasing the individual's vulnerability to stressors, as depicted in Fig 4. Therefore, immune activation induced sensitization of the stress response can be considered to represent a premorbid state. By cumulation or kindling like mechanisms, these reversible alterations may be driven into a more persistent mode during which the changes are accompanied by elevated resting cortisol levels and adrenal hyperactivity. According to this scenario, it can be predicted that the exact timing of stressors relative to the immune activation induced stress vulnerable period is crucial for the development of adrenal hyperplasia and hyperactivity.

We do not imply that this cascade of events is specifically activated by immune stimuli. In fact, major stimuli of other nature (e.g. loss of spouse) can precipitate depression in vulnerable individuals. Nonetheless, we propose that in humans as in rodents, immune stimuli may be particularly powerful triggers to induce long-lasting cross-sensitization to stimuli of a different nature and thereby represent a risk factor for the development of depression. Several observation indicate that immune activation may relate to a specific form of depression.

For instance, multiple sclerosis patients show increased (re)activity of hypothal-

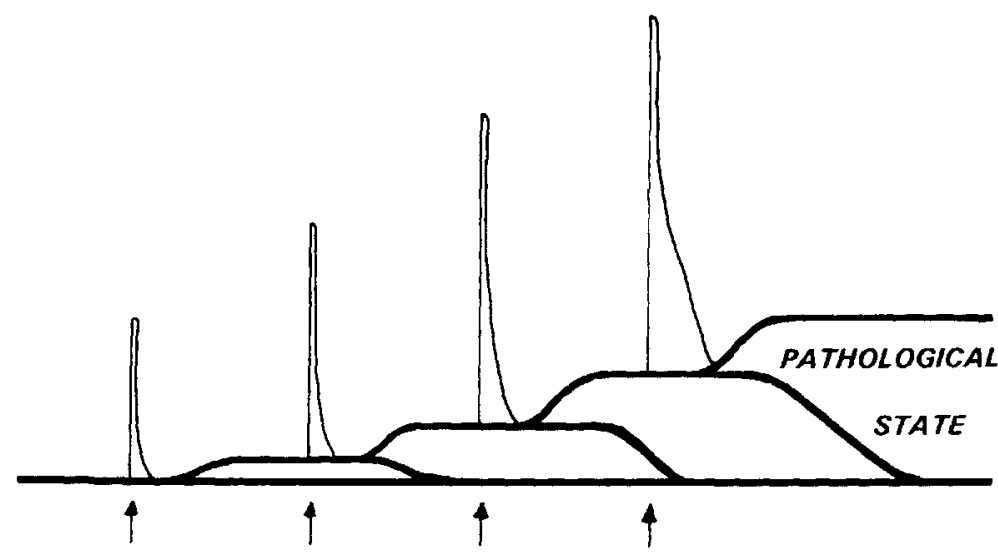

Figure 4. Long-lasting sensitization and its proposed role in the development of psychopathology. Transient activation of the immune system (first arrow) leads to transient activation of the HPA system (thin line), which is followed by a period of adaptive changes in the biological substrate and stress sensitization (bold line). During this period, resting plasma levels of ACTH and cortisol are not affected but hormone responses to other stimuli (second arrow) are exaggerated. This will result in further alterations in the neuroendocrine substrate and prolonged and/or increased stress vulnerability. When additional stimuli follow within the period of stress sensitization, a pathologic state can be reached during which adrenal cortisol production becomes chronically activated. For details see text. 
amic CRH neurons as indicated by increased numbers of CRH expressing neurons and an increase in the fraction of these neurons that co-express AVP (Erkut, Hofman, Ravid, \& Swaab, 1995; Purba, Raadsheer, Hofman, Ravid, Polman, Kamphorst, \& Swaab, 1995; Swaab, 1997). Detailed clinical studies revealed subtle HPA dysregulations e.g. increased resting cortisol levels (Grasser, Moller, Backmund, Yassouridis, \& Holsboer, 1996; Michelson, Stone, Galliven, Magaikou, Chrousos, Sternberg, \& Gold, 1994) and blunted responses to CRH (Michelson et al., 1994) and AVP challenge tests (Wei \& Lightman, 1997). These dysregulations in the HPA system show similarities but are not identical with those found in major depression indicating that partly distinct processes underlie these distortions. Accordingly, major depression is not likely to occur more often in multiple sclerosis patients as compared to the average population, but depressive symptoms categorized as depression due to general medical condition are frequently found in these patients (up to $50 \%$ lifetime risk, Schubert \& Foliart, 1993). In addition, studies on first degree relatives of MS patients show that the genetic basis of depression in these patients is clearly different from that in major depression (Sadovnick, Remick, Allen, Swartz, Yee, Eisen, Farquhar, Hashimoto, Hooge, Kastrukoff, Morrison, Nelson, Oger, \& Paty, 1996) supporting the view that other mechanisms, i.e., immune activation induced events, may play a role in MS associated depression.

Another example refers to aging. In elderly populations, a high incidence of minor depression and depressive symptoms has been found and a low prevalence of major depression (Ernst, 1997). Evidence has been reported to show that the onset and remittance of depression is not related with age per se, but rather with physical illness, functional impairment and numbers of infectious and other disease episodes (Beekman, Kriegsman, Deeg, \& Van Tilburg, 1995a; Beekman, Deeg, Smit, \& Van Tilburg, 1995b). This points to the potential relevance of episodes of immune activation in the development of vulnerability for depression in the elderly. Interestingly, aging is associated with dysregulations of the HPA system (Huizenga, Koper, De Lange, Pols, Stolk, Grobbee, De Jong, \& Lamberts, 1998). Studies on post mortem brains showed that aging is associated with indices of increased (re)activity of hypothalamic $\mathrm{CRH}$ neurons (increased numbers of CRH expressing neurons, increased fraction of vasopressin coproducing CRH neurons (Raadsheer et al., 1993, 1994b, Raadsheer, Oorschot, Verwer, Tilders, \& Swaab, 1994a). Taken together, these findings support the notion that infections or inflammatory episodes that increase with age may induce cumulative long-lasting alterations in hypothalamic CRH neurons that are associated with sensitization to stressors and represent a risk factor for the development of depression.

It should be noted that $\mathrm{CRH}$ neurons may play a role in depression by mechanisms other than those mediated by adrenal steroids. Studies with experimental animals show that symptoms resembling those seen in depression can be induced by intra-cerebral administration of $\mathrm{CRH}$ and are mediated by $\mathrm{CRH}$ receptors in various brainstructures (Chalmers, Lovenberg, Grigoriadis, Behan, \& De Souza, 1996). Similarly, transgenic mice overproducing $\mathrm{CRH}$ show depression related phenotype (Stenzel-Poore, Heinrichs, Rivest, Koob, \& Vale, 1994), whereas CRH deficient and $\mathrm{CRH}$ receptor deficient models show suppression of such symptoms (Muglia, Jacobson, \& Mazjoub, 1996; Smith, Aubry, Dellu, Contarino, Bilezikjian, Gold, Chen, Marchuk, Hauser, Bentley, Sawchenko, Koob, Vale, \& Lee, 1998). Since CRH neurons are known to project to various brain regions including autonomic motor, sensory, and limbic structures, it is conceivable that altered responsiveness of hypothalamic CRH 
neurons affect mood, cognition, and behavior. Following this line of reasoning infection, inflammation, surgery, and other immune challenges may induce neuroplastic changes that are associated with increased power and responsiveness of CRH neurons that may play a role in stress sensitization and consequently in the etiology of mood disorders. In this vein, strategies directed to prevent or correct immune activation induced long-lasting sensitization and neuroplasticity may prove beneficial.

\section{ACKNOWLEDGMENTS}

The authors wish to thank drs P Eikelenboom and JG Hoogendijk, Dept of Psychiatry, Amsterdam for their valuable discussions on disease-associated depression, and drs AN Schoffelmeer and T De Vries, Dept of Pharmacology, Vrije Universiteit, Amsterdam for their stimulating discussions on drug sensitization.

\section{REFERENCES}

Abou-Samra, A. B., Catt, K. J., \& Aguilera, G. (1986). Biphasic inhibition of adrenocorticotropin release by corticosterone in cultured anterior pituitary cells. Endocrinology, 118, 972-977.

Aguilera, G. (1994). Regulation of pituitary ACTH secretion during chronic stress. Frontiers in Neuroendocrinology, 15, 321-350.

Akil, H. A. \& Inés Morano, M. (1995). Stress. In: F. E. Bloom \& D. J. Kupfer (Eds.), Psychopharmacology: The Fourth Generation of Progress (pp. 773-785). New York: Raven Press.

Anisman, H., Kokkinidis, L., Borowski, T., \& Merali, Z. (1998). Differential effects of interleukin (IL)-1-beta, IL-2, and IL-6 on responding for rewarding lateral hypothalamic stimulation. Brain Research, 779 , 177-187.

Antelman, S. M. \& Caggiula A. R. (1996). Oscillation follows drug sensitization: implications. Neurobiology, $10,101-117$

Antelman, S. M., Eichler, A. J., Black, C., \& Kocan, D. (1980). Interchangeability of stress and amphetamine in sensitization. Science, 207, 329-331.

Antelman, S. M., DeGiovanni, L. A., \& Kocan D. (1989). A single exposure to cocaine or immobilization stress provides extremely long-lasting, selective protection against sudden cardiac death from tetracaine. Life Sciences, 44, 201-207.

Bartanusz, V., Jezova, D., Bertini, L. T., Tilders, F. J. H., Aubry, M., \& Kiss, J. (1993). Stress-induced increase in vasopressin and corticotropin releasing factor expression in hypophysiotropic paraventricular neurons. Endocrinology, 132, 895-902.

Beekman, A. T. F., Kriegsman, D. M. W., Deeg, D. H. J., \& Van Tilburg, W. (1995a). The association of physical health and depressive symptoms in the older population. Age and sex differences. Society of Psychiatry and Psychiatric Epidemiology, 30, 32-49.

Beekman, A. T. F., Deeg, D. H. J., Smit, J. H., \& Van Tilburg, W. (1995b). Predicting the course of depression in an older population. Results from a community based study in the Netherlands. Journal of Affective Disorders, 34, 41-49.

Berkenbosch, F., Van Oers, J. W. A. M., Del Rey, A., Tilders, F. J. H., \& Besedovsky, H. A. (1987). Corticotropin releasing factor producing neurons in the rat activated by interleukin-1. Science, 238, 524-525.

Besedovsky, H. O. \& Del Rey, A. (1996). Immune-neuro-endocrine interactions: facts and hypotheses. Endocrine Reviews, 17, 64-102.

Buttini, M. \& Boddeke H (1995). Peripheral lipopolysaccharide stimulation induces interleukin-1beta messenger RNA in rat brain microglial cells. Neuroscience, 65, 523-530.

Buwalda, B., De Boer, S. F., Schmidt, E. D., Sgoifo, A., Van Der Vegt, B. J., Tilders, F. J. H., Bohus, B., \& Koolhaas, J. M. Long-lasting deficient dexamethasone suppression of HPA activation following peripheral CRH challenge in socially defeated rats. J Neuroendocrinology (in press).

Chalmers, D. T., Lovenberg, T. W., Grigoriadis, D. E., Behan, D. P., \& De Souza, E. B. (1996). Corticotropinreleasing factor receptors: from molecular biology to drug design. Trends in Pharmacological Sciences, $17,166-172$. 
Chowdrey, H. S., Larsen, P. J., Harbuz, M. S., Jessop, D. S., Aguilera, G., Eckland, D. J. A., \& Lightman, S. L. (1995). Evidence for arginine vasopressin as the primary activator of the HPA axis during adjuvantinduced arthritis. British Journal of Pharmacology, 116, 2417-2424.

De Goeij, D. C. E., Binnekade, R., \& Tilders, F. J. H. (1992a). Chronic stress enhances vasopressin but not corticotropin releasing factor secretion during hypoglycemia. American Journal of Physiology, 263, E394-E399.

De Goeij, D. C. E., Dijkstra, H., \& Tilders, F. J. H. (1992b). Chronic psychosocial stress enhances vasopressin but not corticotropin releasing factor in the external zone of the median eminence of male rats: relationship to subordinate status. Endocrinology, 131, 847-853.

De Kloet, E. R. \& Joéls, M. (1996). Corticosteroid hormones in neuroprotection and brain damage. Current Opinion in Endocrinology, 3, 184-192.

De Kloet, E. R., Vreugdenhil, E., Oitzl M. S., \& Joëls M. (1997). Glucocorticoid feedback resistance. Trends in Endocrinology and Metabolism, 8, 26-33.

Denicoff, K. D., Durkin, T. M., Lotze, M. T., Quinlan, P. E., Davis, C. L., Listwak, S. J., Rosenberg, S. A., \& Rubinkow, D. R. (1989). The neuroendocrine effects of interleukin-2 treatment. Journal of Clinical Endocrinology and Metabolism, 69, 402-410.

De Vries, T. J., Schoffelmeer, A. N. M., Binnekade, R., Mulder, A. H., \& Vanderschuren, L. J. M. J. (1998). Drug-induced reinstatement of heroin- and cocaine-seeking behavior following long-term extinction is associated with expression of behavioral sensitization. European Journal of Neuroscience, 10, 3565-3571.

Dijkstra, I., Binnekade, R., \& Tilders, F. J. H. (1996). Diurnal variation in resting levels of corticosterone is not mediated by variation in adrenal responsiveness to adrenocorticotropin but involves splanchnic nerve integrity. Endocrinology, 137, 540-547.

Ericsson A., Liu C., Hart R. P., \& Sawchenko, P. E. (1995). Type 1 interleukin-1 receptor in the rat brain: distribution regulation and relationship to sites of IL-1-induced cellular activation. Journal of Comparative Neurology, 136, 681-698.

Ericsson, A., Arias, C., \& Sawchenko, P. E. (1997). Evidence for intramedullary prostaglandin-dependent mechanism in the activation of stress-related neuroendocrine circuitry by intravenous interleukin-1. Journal of Neuroscience, 17, 7166-7179.

Erkut, Z. A., Hofman, M. A., Ravid, R., \& Swaab D. F. (1995). Hyperactivity of hypothalamic corticotropinreleasing hormone (CRH) neurons in multiple sclerosis. J Neuroimmunology, 62, 27-33.

Ernst, C. (1997). Epidemiology of depression in late life. Current Opinion in Psychiatry, 10, 107-112.

Fan, L., Young, P. R., Barone, F. C., Feuerstein, G. Z., Smith, D. H., \& McIntosh, T. X. (1995). Experimental brain injury induces expression of interleukin-1 beta mRNA in rat brain. Molecular Brain Research. $30,125-130$

Gabellec, M. M., Griffais, R., Fillion, G., \& Haour, F. (1995). Expression of interleukin-1 alpha, interleukin1 beta, and interleukin-1 receptor antagonist mRNA in mouse brain: regulation by bacterial Lipopolysacharide treatment. Molecular Brain Research, 31, 122-130.

Gaykema, R. P. A., Dijkstra, I., \& Tilders, F. J. H. (1995). Subdiaphragmatic vagotomy suppresses endotoxininduced activation of hypothalamic corticotropin-releasing hormone neurons and ACTH secretion. Endocrinology, $1.36,4714-4720$.

Grasser, A., Moller, A., Backmund, H., Yassouridis, A., \& Holsboer, F. (1996). Heterogeneity of hypothalamic-pituitary-adrenal system responses to a combined dexamethasone-CRH test in multiple sclerosis. Experimental and Clinical Endocrinology and Diabetes, 104, 31-37.

Hansen, M. K., Taishi, P., Chen, Z., \& Krueger, J. M. (1998). Vagotomy blocks the induction of interleukin-1 beta $\mathrm{mRNA}$ in the brain of rats in response to systemic interleukin-1 beta. Journal of Neuroscience, 18, 2247-2253.

Harbuz, M. S. \& Lightman, S. L.(1992). Stress and the hypothalamo-pituitary-adrenal axis: acute, chronic, and immunological activation. Journal of Endocrinology, 134, 327-339.

Hatzinger, M., Reul, J. M. H. M., Landgraf, R., Holsboer, F., \& Neumann, I. (1996). Combined Dexamethasone/CRH test in rats: Hypothalamo-Pituitary-Adrenocortical system alterations in aging. Neuroendocrinology, 64, 349-356

Holsboer, F. \& Barden, N. (1996). Antidepressants and hypothalamic-pituitary-adrenocortical regulation. Endocrine Reviews, 17, 187-205.

Holsboer, F., Lauer, C. J., Schreiber, W., \& Krieg, J. C. (1995). Altered hypothalamic-pituitary-adrenocortical regulation in healthy subjects at high familial risk for depression. Neuroendocrinology, 62, 340347.

Huizenga, N. A., Koper, J. W., De Lang, P., Pols, H. A., Stolk, R. P., De Jong, F. H., \& Lamberts, S. W. (1998). Interperson variability but intraperson stability of baseline plasma cortisol concentrations, and its 
relation to feedback sensitivity of the hypothalamo-pituitary-adrenal axis to a low dose of dexamethasone in elderly individuals. Journal of Clinical Endocrinology and Metabolism, 83, 47-54.

Joels, M. (1997). Steroid hormones and excitability in the mammalian brain. Frontiers in Neuroendocrinology, $18,2-48$.

Kalivas, P. W. \& Steward, J. (1991). Dopamine transmission in the initiation and expression of drug-and stressinduced sensitization of motor activity. Brain Research Reviews, 16, 223-244.

Kent, S., Bluthé, R. M., Kelly, K. W., \& Dantzer R. (1992). Sickness behavior: a new target for drug development. Trends in Pharmacological Sciences, 13, 24-28.

Kluger, M. J. (1991). Fever: Role of pyrogens and cryogens. Physiological Reviews, 71, 93-127.

Kovács, K. J. \& Sawchenko, P. E. (1996). Sequence of stress-induced alterations in indices of synaptic and transcriptional activation in parvocellular neurosecretory neurons. Journal of Neuroscience, 16, $262-273$.

McEwen, B. S. \& Sapolsky R. M. (1995). Stress and cognitive function. Current Opinion in Neurobiology, 5 , 205-217.

MacLennan, A. J. \& Maier, S. F. (1983). Coping and the stress-induced potentiation of stimulant stereotypy in the rat. Science, 219, 1091-1093.

MacPhee, I. A., Antoni, F., \& Mason, D. W. (1989). Spontaneous recovery of rats from experimental allergic encephalomyelitis is dependent on regulation of the immune system by endogenous adrenal corticosteroids. Journal of Experimental Medicine, 169, 431-445.

Maier, S. F., Goehler, L. E., Fleshner, M., \& Watkins, L. R. (1998). The role of the vagus nerve in cytokineto-brain communication. Annals of the New York Academy of Sciences, 840, 289-300.

Meaney, M. J., Diorio, J., Francis, D., Widdowson, J., Laplante, P., Caldji, C., Sharma, S., Seckl, J. R., \& Plotsky, P. M. (1996). Early environmental regulation of forebrain glucocorticoid receptor gene expressionimplications for adrenocortical responses to stress. Developmental Neuroscience, 18, 49-72.

Meerlo, P., Overkamp, G. J., \& Koolhaas, J. M. (1997). Behavioral and physiological consequences of a single social defeat in Roman high- and low-avoidance rats. Psychoneuroendocrinology, 22, 155-68.

Michelson, D., Stone, L., Galliven, E., Magiakou, M. A., Chrousos, G. P., Sternberg, E. M., \& Gold, P. W. (1994). Multiple sclerosis is associated with alterations in hypothalamic-pituitary-adrenal axis function. Journal of Clinical Endocrinology and Metabolism, 79, 848-853.

Muglia, L., Jacobson, L., \& Mazjoub, J. A. (1996). Production of corticotropin-releasing hormone deficient mice by targeted mutation in embryonic stem cells. Annals of the New York Academy of Sciences, 780 , 49-59.

Munck, A., McGuire, P. M., \& Holbrook, N. J. (1984). Physiological functions of glucocorticoids in stress and their relation to pharmacological actions. Endocrine Reviews, 5, 25-44.

Nemeroff, C. B., Widerlov, E., Bissette, G., Walleus, H., Karlsson, I., Eklund, K., Kilts, C. D., Loosen, P. T., \& Vale, W. (1984). Elevated concentrations of CSF corticotropin-releasing factor-like immunoreactivity in depressed patients. Science, 226, 1342-1344.

Nemeroff, C. B., Krishnan, K. R. R., Recd, D., Leder, R., Beam, C., \& Dunnick, R. (1992). Adrenal gland enlargement in major depression. Archives of General Psychiatry, 49, 384-387.

Nguyen, K. T., Deak, T., Owens, S. M., Kohno, T., Fleshner, M., Watkins, L. R., \& Maier, S. F. (1998). Exposure to acute stress induces brain interleukin-1 $\beta$ protein in the rat. Journal of Neuroscience, 18 , $2239-2246$.

Paulson, P. E., Camp, D. M., \& Robinson, T. E. (1991). Time course of transient behavioral depression and persistent behavioral sensitization in relation to regional brain monoamine concentrations during amphetamine withdrawal in rats. Psychopharmacology, 103, 480-492.

Plata-Salamán, C. R. \& Ilyin, S. E. (1997). Interleukin-1 $\beta$ (IL-1 $\beta$ )-induced modulation of the hypothalamic IL- $1 \beta$ system, Tumor Necrosis Factor- $\alpha$, and Transforming Growth Factor- $\beta 1$ mRNAs in Obese (fa/fa) and Lean $(\mathrm{Fa} / \mathrm{Fa})$ Zucker rats: implications to IL-1 $\beta$ feedback systems and cytokine-cytokine interactions. Journal of Neuroscience Research, 49, 541-550.

Post, R. M. \& Weiss, S. R. B. (1995). The Neuro biology of treatment-resistant mood disorders. In: F. E. Bloom \& D. J. Kupfer (Eds.), Psychopharmacology: The Fourth Generation of Progress (pp.1155-1170). New York: Raven Press.

Purba, J. S., Raadsheer, F. C., Hofman, M. A., Ravid, R., Polman, C. H., Kamphorst, W., \& Swaab, D. F. (1995). Increased number of corticotropin-releasing hormone expressing neurons in the hypothalamic paraventricular nucleus of patients with multiple sclerosis. Neuroendocrinology, 62, 62-70.

Raadsheer, F. C., Sluiter, A. A., Rabid R., Tilders, F. J. H., \& Swaab, D. F. (1993). Localization of corticotropinrelcasing hormone $(\mathrm{CRH})$ neurons in the paraventricular nucleus of the human hypothalamus; agedependent colocalization with vasopressin. Brain Research, 615, 50-62.

Raadsheer, F. C., Oorschot, D. E., Verwer, R. W. H., Tilders, F. J. H., \& Swaab, D. F. (1994a). Age-related 
increase in the total number of corticotropin-releasing hormone neurons in the human paraventricular nucleus in controls and Alzheimer disease: Comparison of the dissector with an unfolding method. Journal of Comparative Neurology, 339, 447-457.

Raadsheer, F. C., Tilders, F. J. H., \& Swaab, D. F. (1994b). Similar age-related increase of vasopressin colocalization in paraventricular corticotropin-releasing hormone neurons in controls and Alzheimer patients. Journal of Neuroendocrinology, 6, 131-133.

Raadshecr, F. C., Hoogendijk, W. J. G., Stam, F. C., Tilders, F. J. H., \& Swaab, D. F. (1994c). Increased numbers of corticotropin releasing hormone expressing neurons in the hypothalamic paraventricular nucleus of depressed patients. Neuroendocrinology, $60,436-444$.

Raadsheer, F. C., Van Heerikhuizen, J. J., Lucassen, P. J., Tilders, F. J. H., \& Swaab, D. F. (1995). Increased corticotrophin-releasing Hormone (CRH) mRNA in the paraventricular nucleus of patients with Alzheimer's disease and depression. American Journal of Psychiatry, 152, 1372-1376.

Rivest, S. (1995). Molecular mechanisms and neural pathways mediating the influence of interleukin-1 on the activity of neuroendocrine CRF motor neurons in the rat. International Journal of Develop mental Neuroscience, 13, 135-146.

Robinson, T. E. (1984). Behavioral sensitization: Characterization of enduring changes in rotational behavior produced by intermittent injections of amphetamine in male and female rats. Psychopharmacology, 84, 466-475.

Robinson, T. E \& Berridge K. C. (1993). The neural basis of drug craving: an incentive sensitization theory of addiction. Brain Research Reviews, 18, 247-291.

Robinson, T. E., Becker, J. B., Young, E. A., Akil, H., \& Castaneda, E. (1987). The effects of footshock stress on regional brain dopamine metabolism and pituitary beta-endorphin release in rats previously sensitized to amphetamine. Neuropharmacology, 26,679-691.

Rothwell, N. J. \& Hopkins S. J. (1995). Cytokines and the central nervous system II: Actions and mechanisms of actions. Trends in Pharmacological Sciences, 18, 130-136.

Rubin, R. T., Phillips, J. J., Sadow, T. F., \& McCracken, J. T. (1995). Adrenal gland volume in major depression. Archives of General Psychiatry, 52, 213-218.

Sadovnick, A. D., Remick. R. A., Allen, J., Swartz, E., Yee, I. M. L., Eisen, K., Farquhar, R., Hashimoto, S. A., Hooge, J., Kastrukoff, L. F., Morrison, W., Nelson, J., Oger, J, \& Paty, D. W. (1996). Depression and multiple sclerosis. Neurology, 46, 628-632.

Sarlis, N. J., Chowdrey, H. S., Stephanou, A., \& Lightman S. L. (1992). Chronic activation of the hypothalamopituitary-adrenal axis and loss of circadian rhythm during adjuvant-induced arthritis in the rat. Endocrinology, 130,1775-1779.

Salta, M. A. Jacobs, R.-A.. Kaltsas, G. A., \& Grossman, A. B. (1998). Endotoxin induces Interleukin-1 $\beta$ and nitric oxide synthase mRNA in rat hypothalamus and pituitary. Neuroendocrinology, 67, 109-116.

Sawchenko, P. E., Brown, E. R., Chan, R. K. W., Ericsson A., Li H-Y., Roland B. L., \& Kovács, K. J. (1996). The paraventricular nucleus of the hypothalamus and the functional neuroanatomy of visceromotor responses to stress. In: G. Holstege, R. Bandler, \& C. B. Saper (Eds.), Progress in Brain Research Vol. 107 (pp.201-222). Elsevicr Science: Amsterdam.

Schmidt, E. D., Janszen, A. W. J. W., Wouterlood, F. G., \& Tilders, F. J. H. (1995a). Interleukin-1 induced long-lasting changes in hypothalamic corticotropin-releasing hormone ( $\mathrm{CRH}$ )-neurons and hyperresponsiveness of the hypothalamus-pituitary-adrenal axis. Journal of Neuroscience, 15, 7417-7426.

Schmidi, E. D., Tilders, F. J. H., Janszen, A. W. J. W., Binnekade, R., De Vries, T. J., \& Schoffelmeer, A. N. M. (1995b). Intermittent cocaine exposure causes delayed and long-lasting sensitization of cocaineinduced ACTH secretion in rats. European Journal of Pharmacology, 285, 317-321.

Schmidt, E. D., Binnekade, R., Janszen, A. W. J. W., \& Tilders, F. J. H. (1996). Short stressor induced long-lasting increases of vasopressin stores in hypothalamic CRH neurons in adult rats. Journal of Neuroendocrinology $8,703-712$.

Schmidt, E. D., Tilders, F. J. H., Binnekade, R., Schoffelmeer, A. N. M., \& De Vries, T. J. Stressor or drug induced hypersecretion of corticosterone is not critically involved in the expression of long-term behavioral sensitization to amphetamine. Neuroscience (in press).

Schubert, D. S. P. \& Foliart, R. H. (1993). Increased depression in multiple sclerosis patients: a metaanalysis. Psychosomatics, 34, 124-130.

Sehic, E. \& Blatteis, C. M. (1996). Blockade of lipopolysacharide-induced fever by subdiaphragmatic vagotomy in guinea pigs. Brain Research, 726, 160-166

Shanks, N., Harbuz, M. S., Jessop D. S., Perks, P., Moore, P. M., \& Lightman, S. L. (1998). Inflammatory disease as chronic stress. Annals of the New York Academy of Sciences, 840, 599-607.

Sherman, A. D. \& Petty, F. (1982). Specificity of the learned helplessness model of depression. Pharmacology Biochemistry and Behavior, 16, 449-454. 
Smith, G. W., Aubry, J. M., Dellu, F., Contarino, A., Bilezikjian, L. M., Gold, L. H., Chen, R., Marchuk, Y., Hauser, C., Bentley, C. A., Sawchenko, P. E., Koob, G. F., Vale, W. W., \& Lee, K. F. (1998). Corticotropin releasing factor receptor 1 -deficient mice display decreased anxiety, impaired stress response, and aberrant neuroendocrine development. Neuron, 20, 1093-1102.

Stenzel-Poore, M. P., Heinrichs, S. C., Rivest, S., Koob, G. F., \& Vale, W. W. (1994). Overproduction of corticotropin releasing factor in transgenic mouse: a genetic model of anxiogenic behavior. Journal of Neuroscience, 14, 2579-2584.

Stewart, J. \& Badiani, A. (1993). Tolerance and sensitization to the behavioral effects of drugs. Behavioral Pharmacology, 4, 289-312.

Swaab, D. F. (1997). Neuro biology and neuropathology of the human hypothalamus. In: F. E. Bloom, A. Björklund, \& T. Hökfelt (Eds.), Handbook of Chemical Neuroanatomy Vol 13 (pp. 39-138). Amsterdam: Elsevier Science.

Tilders, F. J. H. \& Schmidt, E. D. (1998). Interleukin-1-induced plasticity of hypothalamic CRH neurons and long-term stress hyperresponsiveness. Annals of the New York Academy of Sciences, 840, 65-80.

Tilders, F. J. H., Schmidt, E. D., \& De Goeij, D. C. E. (1993). Phenotypic plasticity of CRH neurons during stress. Annals of the New York Academy of Sciences, 697, 39-52.

Tilders, F. J. H., De Rijk, R. H., Van Dam, A. M., Vincent, V. A. M., Schotanus, K., \& Persoons, J. H. A. (1994). Activation of the hypothalamus-pituitary-adrenal axis by bacterial endotoxins: Routes and intermediate signals. Psychoneuroendocrinology, 19, 209-232.

Van Dam, A.-M., Bauer, J., Tilders, F. J. H., \& Berkenbosch, F. (1995). Endotoxin-induced appearance of immunoreactive interleukin-1 $\beta$ in ramified microglia in rat brain: A light and electron microscopical study. Neuroscience, 3, 815-826.

Van Dam, A-M., De Vries, H. E., Kuiper, J., Zijlstra, F. J., Tilders, F. J. H., \& Berkenbosch, F. (1996). Interleukin-1 receptors on rat brain endothelial cells: a role in neuro-immune interaction? FASEB Journal, 10,351-356.

Van Dijken, H. H. (1992). Once is enough. An animal study on temporal aspects of stress-induced behavioral and neuroendocrine changes. (Doctoral thesis). Monnickendam: Gravo Groep (pp. 1-175).

Van Dijken, H. H., Mos, J., Van der Heijden, J. A. M., \& Tilders, F. J. H (1992a). Characterization of stressinduced long-term behavioral changes in rats: evidence in favor of anxiety. Physiology and Behavior, $52,945-951$.

Van Dijken, H. H., Tilders, F. J. H., Olivier, B., \& Mos, J. (1992b). Effects of anxiolytic and antidepressant drugs on long-lasting behavioral deficits resulting from one short stress experience in male rats. Psychopharmacology, 109, 395-402.

Van Dijken, H. H., Van der Heijden, J. A. M., Mos, J., \& Tilders, F. J. H. (1992c). Inescapable footshocks induce progressive and long-lasting behavioral changes in male rats. Physiology and Behavior, 51, 787-794.

Van Dijken, H. H., De Goeij, D. C. E., Sutanto, W., Mos, J., De Kloet, E. R., \& Tilders, F. J. H. (1993). Short inescapable stress produces long lasting changes in the pituitary-adrenal axis of adult male rats. Neuroendocrinology, 58: 57-64.

Van der Meer, M. J. M., Sweep, C. G. J., Pesman, G. J., Tilders, F. J. H., \& Hermus, A. R. M. M. (1996). Chronic stimulation of the hypothalamus-pituitary-adrenal axis in rats by interleukin- $1 \beta$ : central and peripheral mechanisms. Cytokine, 8, 910-919.

Van Oers, J. W. A. M., Hinson, J. P., Binnekade, R., \& Tilders, F. J. H. (1992). Physiological role of Corticotropin Releasing Factor in the control of ACTH mediated corticosterone release from the rat adrenal gland. Endocrinology, 130, 282-288.

Von Bardeleben, U., Holsboer, F., Stalla, G. K., \& Müller, O. A. (1985). Combined administration of human corticotropin-releasing factor and lysine vasopressin induces cortisol escape form dexamethasone suppression in healthy subjects. Life Sciences, 37, 1613-1618.

Von Bardeleben, U., Stalla, G. K., Müller, O. A., \& Holsboer, F. (1988). Blunting of ACTH response to human CRH in depressed patients is avoided by metyrapone pretreatment. Biological Psychiatry, 24, 782-786.

Watanabe, T., Makisuma, M., Tan, N., Nakamori, T., Hakaura, S., \& Murakami, N. (1995). Febrile responses induced in adrenalectomized rats by administration of interleukin-1 beta or prostaglandin $\mathrm{E}_{2}$. Journal of Physiology, 484, 767-775.

Watkins, L. R., Wiertelak, E. P., Goehler, L. E., Mooney-Heiberger, K., Martinez, J., Furness, L., Smith, K. P., \& Maier, S. F. (1994). Neurocircuitry of illness-induced hyperalgesia. Brain Research, 639, 283-299.

Wei, T. \& Lightman, S. L. (1997). The Neuroendocrine axis in patients with multiple sclerosis. Brain, 120, $1067-1076$.

Weinstock, M. (1997). Does prenatal stress impair coping and regulation of hypothalamus-pituitary-adrenal axis. Neuroscience and Biohavioral Reviews, 21, 1-10. 
Whitnall, M. H. (1993). Regulation of the hypothalamic corticotropin releasing hormone neurosecretory system. Progress in Neurobiology, 40, 573-629.

Wilcox, R. A., Robinson, T. E.. \& Becker, J. B. (1986). Enduring enhancement in amphetamine-stimulated striatal dopamine release in vitro produced by prior exposure to amphetamine or stress in vivo. European Journal of Pharmacology, 124, 375-376.

Young, E. A., Haskett, R. F., Murphy-Weinburg, V., Watson, S., \& Akil, H. (1991). Loss of glucocorticoid fast feedback in depression. Archives of General Psychiatry, 48, 693-699. 